\title{
Relationship between Emotional Labor Behavior and Burnout Level of Football Coaches
}

\author{
Ersan Tolukan ${ }^{1}$ \\ ${ }^{1}$ Department of Sport Sciences, Faculty of Health Sciences, Ankara Yıldırım Beyazıt University, Turkey \\ Correspondence: Ersan Tolukan, Department of Sport Sciences, Faculty of Health Sciences, Ankara Yildırım \\ Beyazit University, Turkey
}

Received: February 5, 2019

Accepted: March 15, 2019

Online Published: March 19, 2019

doi:10.5430/ijhe.v8n2p7

URL: https://doi.org/10.5430/ijhe.v8n2p7

\begin{abstract}
In the scope of this research, it is aimed to determine emotional labor behavior and burnout level of football coaches and to examine the relationship between them. In this study conducted in relational survey model, Emotional Labor Scale developed by Diefendorff et al. (2005) and adapted to Turkish by Basım and Beğenirbaş (2012), and Maslach Burnout Sclae developed by Maslach and Jackson (1981) and adapted to Turkish by Ergin (1992) were applied to 321 voluntary participants. Descriptive statistics (number of participants, minimum, maximum, mean, standard deviation) regarding emotional labor and burnout levels of participants were calculated. Besides, pearson correlation coefficient was calculated with the aim of determining the level of relation between the sub-dimensions of emotional labor and burnout. $p$ significance level in difference tests was taken as 0,05. Research results showed that burnout levels of coaches were low; as the sub-dimensions of emotional labor scale, the factors of deep acting and genuine emotions were high, and the factor of surface acting was low. According to the correlation results, it was determined that there was a low level negative relation between their burnout levels and surface acting behavior and a low level positive significant relation between deep acting behavior and genuine emotions.
\end{abstract}

Keywords: emotional labor, burnout, football, coaching

\section{Introduction}

Nowadays, a lot of profession areas require face-to-face and close interaction. It is observed that the individuals working in these professions whose aspects of human affairs are intense have emotional reactions up to emotional exhaustion (Sağlam, 2011). That the reactions such as emotional labor behaviors and burnout are mostly seen in the professions getting in peer-to-peer and intense contact with people makes the examination of the employees of sports institutions important.

Coaches working in football clubs which have an important position in sports sector are the individuals bearing emotional labor responsibility and burnout predominantly. With this responsibility, the problems can occur because of the emotional contradiction arising from the differences between real emotions and the ones felt in working life. In addition to this, period of unhappiness growing out of problems concerning business or being experienced individually and called as burnout can cause negative results. Coaches have a crucial place in groups who experience burnout in football teams because the necessity of direct communication with athletes can lead to burnout due to the factors based on individuals, athletes and workload while it brings the use of emotional labor into the forefront.

For this reason, coaches who are responsible for the team atmosphere should regulate the relations between athletes and the relations between themselves very well in order to provide success and should behave in a sensitive manner in this issue (Lazar, 2001).

Thereby, if the coaches are considered as the director who educate his athletes and team in line with the specific purposes and focus on success (Akbulut \& Altınkök, 2018), the examination of their emotional labor behaviors and burnout levels has importance.

\subsection{Emotional Labor}

The notion of emotional labor firstly conceptualized by Hochschild (1983) is used as the effort of managing emotions that an individual feels and expresses to the others according to the necessities of his business processes and professions. 
Morris and Feldman (1997), on the other hand, define emotional labor as the individual effort, planning and controlling that is made to have employees reflect their emotions that is wanted to be shown by the organization to the interpersonal interactions.

In the most general definition, the notion of emotional labor which can be stated as the regulation of authentic emotions to reflect appropriate emotions in workplace environment (Isenbarger \& Zembylas, 2006) is quite important for the organization success (Basim, et. al., 2013).

When there are differences between authentic emotions and the ones expected in business life, we are expected to show emotions that the professional position require, and in this case that should be made effort for the management of emotions (Theodosius, 2008). For this reason, individuals are required to regulate their emotions in the workplace environment. Emotional labor, which is defined as the reflection of appropriate emotions being suitable for the purposes of workplace by suppressing authentic emotions, has an important place in the business life (Brown, 2011).

While Hochschild (1983) identifies emotional labor in two-dimensional structure composed of surface and deep behaviors, Ashforth and Humphrey (1993) state it in three dimensions such as surface, deep and authentic behavior.

Surface labor behavior is that an employee pretends to have emotions that they do not really have; that is to say, it is the reflection of pretended emotions by employees (Kaya \& Serçeoğlu, 2013). In other words, surface labor behavior is the different emotional reflections by hiding authentic emotions because of some reasons. Deep behavior, on the other hand, is called as deep acting or emotional effort. Deep acting behavior is the adaptation of an individual's inner feelings to the ones that require him to be displayed (Eroğlu, 2014). That is to say, it is described as the endeavoring of an individual to bring his authentic emotions into conformity with the expected behaviors, and to experience the feelings that should be reflected personally (Beğenirbaş \& Basım, 2013). As another dimension, authentic emotions are stated by Ashforth and Humphrey (1993) as the observance of the emotional behavior rules expected from the individuals without effort and the reflection of their emotions genuinely needed to be reflected to the behavior.

In the general sense, the notion of emotional labor includes necessities of suppression so as to manage employees' being in the position of convincing another person, or facial expressions and physical appearances which provide showing situations appropriately in the other people's minds, according to the expectations of the ones who get service (Hochschild, 1983; Eroğlu, 2014).

\subsection{Burnout}

As a notion leading negations in professional business life of individuals and in their relations with the others, burnout has become an important problem for today's world (Eroğlu, 2014).

The concept of burnout is explained by Maslach as a syndrome revealing itself in the way that individuals in constant face-to-face professional interaction feel emotional burnout, they are desensitized towards the others encountered as part of their jobs and their senses of achievement and efficiency decrease (Aksel \& Bağc1, 2017).

According to the researches on burnout syndrome level, burnout level increases when the time spent with the people encountered in the workplace extends, the employees frequently interact with the same people, the number of person who they give service increases, the people getting service have great problems and the employees have face-to-face interaction with these people (Cemaloğlu \& Şahin, 2007).

This situation not only damages people who experience it but also destroys everything and everybody around an individual. According to Maslach, burnout (negative states such as anxiety, depression, self-esteem and mental health problems) can cause psychological breakdown (Konakay, 2013).

Burnout, which is conceptualized as the reactions given in an emotional sense, is classified into three sub-dimensions such as emotional exhaustion, depersonalization and lack of personal accomplishment (Maslach et. al., 2001). Emotional exhaustion comes into prominence as a factor which affects individuals negatively in terms of orientating psychologically and physically and productivity (Y1ld1z, 2012). As a second sub-dimension, depersonalization occurs in consequence of the communication between individuals. To Maslach, an individual who experiences this syndrome intensely sees this state as a rescuer by having the idea that he feels incomplete in terms of problem solving and cooperation (Maslach \& Goldberg, 1998). Lack of personal accomplishment arising out of different reasons such as intense work pressure of individuals can cause some negative situations such as feeling incomplete and burnout physically and emotionally. This dimension is the third one which causes individual's burnout syndrome in the workplace to reach top-level (Gündüz, 2005). 


\subsection{The Relationship between Emotional Labor and Burnout}

As a result of researches on emotional labor behavior, the most important negative conclusion of it is the burnout syndrome (Özgen, 2010). Khan (2012), who examined the relationship between employees' emotional labors and burnouts, found out that they are closely interrelated.

Grandey determined that there was a directly proportional relation between emotional labor and burnout and that the emotional labor caused burnout in employees. Employees can feel physical fatigue and emotional exhaustion as they are always obliged to control their feelings to show expected emotional expressions (Grandey, 2000).

In other words, the employee who tries to reveal appropriate behaviors by suppressing their authentic emotions dissatisfaction, burnout, overloaded role, and affective disharmony (Duran \& Gümüş, 2013).

Because of this disharmony, individual's emotional exhaustion comes into question; therefore, he begins to depersonalize towards the others and loses his sense of success. These three factors in point are stated as "burnout" in literature. This is all to say, the more emotional labor of an individual increases, the more burnout level is affected by this (Aksel \& Bağc1, 2017).

In many researches on the relationship between emotional labor and burnout level in different occupational groups (Isenbarger \& Zembylas, 2006; Zhang \& Zhu, 2008; Choi \& Kim, 2015; Kaplan \& Ulutaş, 2016; Aziz et. al., 2018; Koçak \& Gürsoy, 2018; Lee \& Chelladurai, 2018), significant relations between emotional labor and different dimensions of burnout were determined.

\section{Method}

\subsection{Research Model}

In this research, it was aimed to examine the relationship between emotional labor levels and burnout levels of coaches. In this context, it was organized in relational survey model that is one of the quantitative research methods. Because of the fact that the relationship between variables are defined, correlational researches are characterized as a type of descriptive research (Frankel \& Wallen, 2009). In the relational survey models that are also called as correlational, the alteration of two or more variables is examined together (Büyüköztürk, Çakmak, Akgün, Karadeniz \& Demirel, 2012).

\subsection{Population and Sample}

The population of the research consists of 862 coaches attending 2018 visa seminar in 1810 coaches who are affiliated to Turkish Football Coaches Association of Ankara. The research sample is composed of 266 coaches determined by sampling method which can be easily found by taking $\% 95$ confidence interval and 0.05 error margin into consideration on the basis of population identified in the scope of research population. The required sample size in constituting research sample was calculated by the equation suggested by Büyüköztürk et. al. (2012).

$$
n=\frac{n_{0}}{1+\frac{n_{0}}{N}}
$$

Equation 2.1. Prediction of sample size in continuous variables

Equation is calculated by $\mathrm{n}_{0}=\left(\mathrm{t}^{2} \mathrm{PQ}\right) / \mathrm{d}^{2}$ in 2.1 . When the $\mathrm{p}$ significance value is taken 0,05 , pq becomes equal to 0,25 and $\mathrm{t}$-score is 1,96 . Thus, it is calculated as $\mathrm{n}_{0}=384,16$ in the 0,05 significance level (Büyüköztürk, Çakmak, Akgün, Karadeniz, \& Demirel, 2012). When $\mathrm{n}_{0}$ is put into formula, it is calculated as:

$$
\mathrm{n}=\frac{384,16}{1+\frac{384,16}{862}}=265,73=266
$$

In the scope of this research, it is seen that the attained sample has the ability of representing target population of the study which is determined by the convenience sampling method and in which 321 coaches are reached. Convenience sampling is the sampling that is done on the available and voluntary individuals who are in the immediate circle and easy to reach (Erkuş, 2013).

\subsection{Data Collection Tools}

The data of this research is collected by Personal Information Form, Emotional Labor Scale, Maslach Burnout Scale. 


\subsubsection{Emotional Labor Scale}

With the aim of determining emotional labor levels of the coaches, Emotional Labor Scale developed by Diefendorff et. al. (2005) and adapted to Turkish by Basım and Beğenirbaş (2012) was used. In the scope of Turkish adaptation, it consists of the findings related to the validity and reliability values. The study was carried out by the data extracted from two different samples $(\mathrm{n}=152, \mathrm{n}=273)$. As a result of analyses, it was determined that it displayed three-factor structure including sub-dimensions such as surface acting, deep acting, and authentic emotions. In addition to this, criterion referenced validity of the scale was also provided by taking advantage of burnout scale. On the other hand, in consequence of reliability analyses, Cronbach Alpha coefficient for the whole scale was calculates as , 80 for both samples. The results obtained showed that the adapted scale could be validly and reliably used in the measurement of emotional labor tendency for occupational life in Turkey. As a result of first-level confirmatory factor analysis, it was concluded that fit index values were compatible and the relationship between sub-factors of the scale was not so high. In this regard, total score could not be reached due to the fact that sub-factors of the scale were independent of each other.

\subsubsection{Maslach Burnout Scale}

In the scope of the research, Maslach Burnout Scale developed by Maslach and Jackson (1981) and adapted to Turkish by Ergin (1992) was used in order to determine burnout levels of coaches. In this scale, there are 22 items including emotional exhaustion, depersonalization, and lack of personal accomplishment. The items are graded in 5 point likert scale. Because the items which are in the dimension of lack of personal accomplishment include negative statements, all the items are coded reversely. Maslach Burnout Scale was adapted to Turkish by Ergin (1992) and cronbach alpha coefficients were calculated as 0,83 for emotional exhaustion, 0,71 for depersonalization, and 0,72 for lack of personal accomplishment by the data obtained from the groups consisting of 552 doctors and nurses.

\subsection{Data Analysis}

The data collected in the scope of the research were processed into SPSS-21 packaged software. Before we examined the relationship between emotional labor levels and burnout levels of coaches, normality and Levene homogeneity test was made to decide whether the distribution was parametric or nonparametric. Skewness and kurtosis value was investigated to test normal distribution hypothesis of the scores regarding sub-factor of the scale belonging to the data obtained from the scale. When it was compared with $p<, 05$ value by making the Kolmogorov-Smirnov Z Test for normality of the distribution and Levene Homogeneity Tests for homogeneity of the distribution, it was found that there was no significant deviation; that is to say, the distributions of the scores obtained from the scale were normal and homogeny. At the same time, it is stated that skewness and kurtosis coefficients as a measure of normality hypothesis can be accepted to be in between -1 and +1 (Morgan, Leech, Gloeckner \& Barrett, 2004). That the measurements are made in the level of interval and ratio scale supports the parametric test assumptions (Köklü, Büyüköztürk \& Bökeoğlu, 2007). In this case, the relationship between emotional labor levels of coaches and their burnout was investigated by Pearson correlation analysis. The descriptive statistic results (minimum value, maximum value, mean and standard deviation) of the scores obtained from the scales were also included.

\section{Results}

\subsection{First Sub-Problem: What is the Level of Emotional Labor of Coaches?}

Table 1. Descriptive Statistic Results regarding Sub-Factors of Emotional Labor Sclae of Coaches

\begin{tabular}{lllllll}
\hline Emotional Labor Scale & Number of Items & N & Minimum & Maximum & $\overline{\mathrm{X}}($ Mean $)$ & $\mathrm{S}$ \\
\hline Surface Acting & 6 & 321 & 6,00 & 26,00 & $12,31(2,05)$ & 4,96 \\
Deep Acting & 4 & 321 & 7,00 & 20,00 & $16,36(4,09)$ & 3,13 \\
Authentic Emotions & 3 & 321 & 8,00 & 15,00 & $13,08(4,36)$ & 1,83 \\
\hline
\end{tabular}

Intervals (5-1)/5=0,80 Criterion: 1,00-1,79=Too Low; 1,80-2,59=Low; 2,60-3,39=Medium; 3,40-4,19=High; 4,20-5,00=Too High

According to Table 1 indicating the distributions of emotional labor levels of coaches, emotional labor levels of coaches in the sub-factor "surface acting" have the mean of $\bar{X}=12,31(\mathrm{~S}=4,96)$. It is seen that they have the low-level surface acting with the mean of criterion score 2,05 occurring as a result of division of item number.

It is seen that coaches' emotional labor levels in terms of sub-factor "deep acting" have the mean of $\bar{X}=16,36$ $(S=3,13)$. Besides, they have the high-level deep acting with the mean of criterion score 4,09 occurring as a result of division of item number. 
Their emotional labor levels in terms of sub-factor "authentic emotions" have the mean of $\bar{X}=13,08(S=1,83)$ and they have the too high-level authentic emotions with the mean of criterion score 4,36 occurring as a result of division of item number.

\subsection{Second Sub-Problem: What is the Level of Burnouts of Coaches?}

Table 2. Descriptive Statistic Results regarding Sub-Factors and Overall of Maslach Burnout Scale of Coaches

\begin{tabular}{lllllll}
\hline Maslach Burnout Scale & Number of Items & $\mathrm{N}$ & Minimum & Maximum & $\overline{\mathrm{X}}($ Mean $)$ & $\mathrm{S}$ \\
\hline Emotional Exhaustion & 9 & 321 & 9,00 & 35,00 & $17,35(1,93)$ & 5,89 \\
Depersonalization & 5 & 321 & 5,00 & 19,00 & $8,66(1,73)$ & 3,03 \\
Lack of Personal Accomplishment & 8 & 321 & 8,00 & 29,00 & $15,57(1,95)$ & 5,12 \\
Overall Scale & 22 & 321 & 23,00 & 67,00 & $41,58(1,89)$ & 11,11 \\
\hline
\end{tabular}

Intervals (5-1)/5=0,80 Criterion: 1,00-1,79=Too Low; 1,80-2,59=Low; 2,60-3,39=Medium; 3,40-4,19=High; 4,20-5,00=Too High

In Table 2, the distributions of burnout levels of coaches are examined. Their burnout levels in terms of sub-factor "emotional exhaustion" have the mean of $\overline{\mathrm{X}}=17,35(\mathrm{~S}=5,89)$ and they have the low-level emotional exhaustion with the mean of criterion score 1,93 occurring as a result of division of item number.

It is seen that coaches' burnout levels in terms of sub-factor "depersonalization" have the mean of $\bar{X}=8,66(S=3,03)$. In addition to this, they have the too low-level depersonalization with the mean of criterion score 1,73 occurring as a result of division of item number.

Their burnout levels in terms of sub-factor "lack of personal accomplishment" have the mean of $\bar{X}=15,57(S=5,12)$ and they have the low-level lack of personal accomplishment with the mean of criterion score 1,95 occurring as a result of division of item number.

Maslach burnout scale indicates that the burnout levels of coaches are $\bar{X}=41,58(S=11,11)$ and they have low-level burnout with the mean of criterion score 1,89 occurring as a result of division of item number.

3.3 Third Sub-Problem: Is There a Relationship between Burnout Levels and Emotional Labor Levels of Coaches?

Table 3. Pearson Correlation Analysis Results regarding the Relationship between Burnout Levels and Emotional Labor Levels of Coaches

\begin{tabular}{lllll}
\hline & & Surface Acting & Deep Acting & Authentic Emotions \\
\hline \multirow{2}{*}{ Emotional Exhaustion } & $\mathrm{r}$ & $0,15\left(^{*}\right)$ & $-0,14\left(^{*}\right)$ & $-0,04$ \\
& $\mathrm{p}$ &, 004 &, 005 &, 237 \\
Depersonalization & $\mathrm{r}$ & $0,22\left(^{*}\right)$ & 0,012 & $-0,11\left(^{*}\right)$ \\
& $\mathrm{p}$ &, 000 &, 418 &, 023 \\
Lack of Personal Accomplishment & $\mathrm{r}$ & $-0,06$ & $-0,25\left(^{*}\right)$ & $-0,41\left(^{*}\right)$ \\
& $\mathrm{p}$ &, 157 &, 000 &, 000 \\
Overall Maslach Burnout Scale & $\mathrm{r}$ & $0,11(*)$ & $-0,19\left(^{*}\right)$ & $-0,24\left(^{*}\right)$ \\
& $\mathrm{p}$ &, 021 &, 000 &, 000 \\
\hline
\end{tabular}

In Table 3, the relationship between burnout levels and emotional labor levels of coaches are examined. There is a significant and positive yet low-level relationship between burnout levels concerning emotional exhaustion and emotional labor level concerning surface acting according to $\mathrm{r}=0,15, \mathrm{p}<, 05$. There is also a significant and negative yet low relationship between emotional exhaustion and deep acting related to emotional labor level according to $\mathrm{r}=-0,14, \mathrm{p}<, 05$. Lastly, there is no significant relationship between emotional exhaustion and authentic emotions regarding emotional labor levels according to $\mathrm{p}>, 05$.

It is also seen that there is a positive and significant yet low-level relationship between burnout levels and emotional labor levels regarding surface acting according to $r=0,22, p<, 05$. On the other hand, there is no relationship between burnout levels and deep acting regarding emotional labor level according to $p>, 05$. It is seen that there is a significant and negative yet low-level relationship between burnout levels and authentic emotions related to emotional labor levels. 
There is no relationship between burnout levels concerning lack of personal accomplishment and emotional labor level concerning surface acting according to $\mathrm{p}>, 05$; however, it has the negative and significant yet low-level relationship with deep acting regarding emotional labor level according to $r=-0,25, p<, 05$. The relationship between burnout levels and emotional labor levels is negative and significant yet medium-level according to $r=-0,41, p<, 05$.

It is also seen that there is a positive and significant yet low-level relationship between burnout levels and emotional labor levels regarding surface acting according to $\mathrm{r}=0,11, \mathrm{p}<, 05$. Besides, there is a negative and significant yet low-level relationship between burnout levels and deep acting regarding emotional labor level according to $\mathrm{r}=-0,19$, $\mathrm{p}>, 05$. It is seen that there is a significant and negative yet low-level relationship between burnout levels and authentic emotions related to emotional labor levels according to $r=-0,24, \mathrm{p}<, 05$.

\section{Discussion}

In the scope of research, it was aimed to determine emotional labor and burnout levels of coaches and to examine the relationship between some variables. Accordingly, descriptive statistics concerning emotional labor and burnout levels of coaches were firstly calculated, and the mean score $(1,89)$ regarding the overall burnout scale of coaches was in low-level. It was also determined that "emotional exhaustion" $(1,93)$ and "lack of personal accomplishment" $(1,95)$ were in low level and "depersonalization" $(1,75)$ was in too low-level. When the sub-dimensions of emotional labor scale of coaches were examined, it was determined that "surface acting" $(2,05)$ was in low level, "deep acting" $(4,09)$ was in high level and "authentic emotions" $(4,36)$ was in too high level.

With reference to these results, it can be said that coaches generally experience burnout in low level in their business life; however, they can suppress their stress and the negative situations in business life. Indeed, football coaches interact with directors, media, fans, referees, and athletes. This interaction puts the pressure on coaches and it causes to be unavoidable that they undergo stress in their business life. According to Maslach (2003), burnout especially in business life is a psychological syndrome including a long-term reaction developed against the stress factors in workplace. Additionally, that the dimension of depersonalization is in low level can result from the need for peer-to-peer and close relation with the athletes as part of coaches' jobs. Likewise, depersonalization is stated as the tendency of keeping an employee's distance with the people that are serviced (Maslach et. al., 2001). In the same vein of our research findings, Uğur (2014) states in his study on burnout levels of active football coaches that they save their energies physically and psychologically and their burnout levels are low as they do their jobs with love despite a lot of difficulties and pressures.

At the same time, that the coaches' reflection of acting and authentic emotions behavior is in high level and their reflection of surface acting is in low level arises out of that coaches are attentive to the communication with their athletes. Surface behavior is the reflection of emotions that are not really felt or the non-reflection of emotions really felt (Avc1 \& Boylu, 2010). Attitudes and behaviors of coaches and their communication link is a kind of method including psychological factors affecting performance of athletes positively or negatively (Lazar, 2001).

When the correlation results of data obtained from emotional labor scale and burnout scale of coaches were examined, it was determined that there was a positive yet low-level relationship between "surface acting" sub-dimension of emotional labor scale and emotional exhaustion, depersonalization, and the overall burnout scale. Besides, the negative yet low-level relationship between "deep acting" sub-dimension of emotional labor scale and emotional exhaustion, lack of personal accomplishment, and the overall burnout scale was found. It was also determined that there was a negative yet medium-level relationship between "authentic emotions" sub-dimension of emotional labor scale and lack of personal accomplishment while there was a negative yet low-level relationship between authentic emotions and depersonalization and the overall burnout scale.

If we are to state in general, when the acting and authentic emotions behavior of coaches increases, their burnout levels decrease in low level. On the other hand, when their surface acting behavior increases, their burnout levels increase in low level. Related to our findings, Köse et. al. (2011) state that surface behavior increases emotional exhaustion and depersonalization levels. An individual who reflects surface acting behavior experiences dissatisfaction, exhaustion, overloaded role feeling, and affective disharmony by trying to show appropriate behaviors and suppressing his real emotions (Duran \& Gümüş, 2013). If the really-felt emotions and the reflected behaviors are different from each other, role conflict stated as affective disharmony is experienced. This situation is about the conflict between the possessed values of an individual and the position where he wants to be (role expectation). As a conclusion, it causes stress and emotional exhaustion accordingly (Güngör, 2009). In other words, individuals can feel emotional and physical fatigue as they have to control their emotions continuously in order to reflect the expected emotional expressions (Grandey, 2000). 
In parallel with our research, Zhang and Zhu (2008) state that the reflection of authentic emotions has the negative relationship with emotional exhaustion and deep acting while it shows positive relationship with surface acting. Youngmi (2016) who examines the relationship between emotional labor and burnout levels of teachers finds out that there is a positive relationship between them. In addition to this, the positive relationship between surface behavior and emotional exhaustion has the highest value. When the related literature is viewed, it is seen that surface acting has positive and significant relationship with emotional exhaustion and depersonalization in different occupational groups (Grandey, 2003; Oral \& Köse, 2011; Eroğlu, 2014; Serin, 2014; Yılmaz et. al., 2015).

The significant relationships between burnout levels and sub-dimensions of emotional labor are expected to be studied. Khan (2012) who examines the relationship between emotional labor and burnout shows that there is a close relationship between emotional labor and burnouts of employees.

As a conclusion, it was determined that burnout levels of the football coaches in the scope of the research were low, their surface acting and authentic emotions were in high level, and the factor of surface acting was in low level. At the same time, it was found out that there was a negative and significant yet low-level relationship between burnout levels and surface acting behaviors of coaches and a positive and significant yet low-level relationship between deep acting and authentic emotions behavior. When the literature is investigated, the most negative result of emotional labor behaviors is the burnout syndrome (Özgen, 2010). Similarly, Grandey (1999) states that there is a directly proportional relationship between emotional labor and burnout and emotional labor causes burnout in employees.

In this scope, the limits of coaches' roles should be determined, role conflicts should be minimized as far as possible and some activities towards keeping their internal motivations high should be done in order not to cause emotional exhaustion that can lead to important problems for coaches.

\section{References}

Akbulut, A., \& Altınkök, M. (2018). The examination of burnout levels of boxing trainers. Journal of Sport, Education and Recreation, 1(1), 31-41.

Aksel, İ., \& Bağcı, Z. (2017). A study on the relationship between employees' Emotional labor and emotional exhaustion. MANAS Journal of Social Studies, 6(4), 463-473.

Ashforth, B. E., \& Humphrey, R. H. (1993). Emotional labor in service roles: Influence of identity. Academy of Management Review, 18, 88-115. https://doi.org/10.2307/258824

Avc1, U., \& Boylu, Y. (2010). Emotional labor scale validation on Turkish tourism workers. Journal of Travel and Hospitality Management, 7(2), 20-29.

Aziz, S., Widis, A., \& Wuensch, K. (2018). The association between emotional labor and burnout: The moderating role of psychological capital. Occupational Health Science, 2(4), 365-383.

Basım, H. N., \& Beğenirbaş, M. (2012). Emotional labor in work life: A study of scale adaptation. Management and Economics: Celal Bayar University the Journal of Faculty of Economics and Administrative Sciences, 19(1), 77-90.

Basım, H. N., Begenirbaş, M., \& Yalçın, C. R. (2013). Effects of teacher personalities on emotional exhaustion: Mediating role of emotional labor. Educational Sciences: Theory \& Practice, 13(3), 1477-1496. https://doi.org/10.12738/estp.2013.3.1509

Beğenirbaş, M., \& Basım, H. N. (2013). The role of demographic variables on emotional labor: An empirical study, Çankaya University Journal of Humanities and Social Sciences, 10(1), 48-49.

Brown, L. E. F. (2011). Emotion matters: Exploring the emotional labor of teaching. Doctoral dissertation, University of Pittsburgh.

Büyüköztürk, Ş., Çakmak, E. K., Akgün, Ö. E., Karadeniz, Ş., \& Demirel, F. (2014). Scientific research method. Ankara: Pegem Academy.

Cemaloğlu, N., \& Şahin, D. E. (2007). A study of the teacher's burnout level according to various variables. Kastamonu Education Journal, 15(2), 465-484.

Choi, Y. G. \& Kim, K. S. (2015). The influence of emotional labor on burnout: Centered on the stress coping strategy and moderating effect of social support. International Journal of Social Science and Humanity, 5(7), 583-588. https://doi.org/10.7763/IJSSH.2015.V5.522

Diefendorff, J. M., Croyle, M., \& Gosserand, R. H. (2005). The dimensionality and antecedents of emotional labor 
strategies. Journal of Vocational Behavior, 66, 339-357.

Duran, E., \& Gümüş, M. (2013). Effects of tourism undergraduate students' Emotional labor experiences on their career preferences. Dokuz Eylül University Journal of Institute of Social Sciences, 15(2), 233-251.

Ergin, C. (1992). The doctors and nurses in burnout and adaptation of the maslach burnout scale. VII. National Psychology Congress scientific studies, 22-25 September, Ankara.

Erkuş, A. (2013). Scientific research process for behavioral sciences. Ankara: Seçkin.

Eroğlu, Ş. G. (2014). A research on the relation between emotional labor and burnout in organizations. Pamukkale University Journal of Social Sciences Institute, 19, 147-160.

Fraenkel, J. R., \& Wallen, N. E. (2009). How to design and evaluate research in education, seventh edition. Boston: McGraw-Hill.

Grandey, A. (2003). When "the show must go on": Surface acting and deep acting as determinants of emotional exhaustion and peer-rated service delivery. Academy of Management Journal, 46(1), 86-96. https://doi.org/10.5465/30040678

Grandey, A. A. (1999) The effects of emotional labor: Employee attitudes, stress and performance, Doctoral dissertation, Colorado State University, USA.

Grandey, A. A. (2000). Emotion regulation in the workplace: A new way to conceptualize emotional labor. Journal of Occupational Health Psychology, 5(1), 95-110.

Gündüz, B. (2005). Burnout in primary teachers. Mersin University Journal of the Faculty of Education, 1(1), 152-166.

Güngör, M. (2009). The phenomenon of emotional labour: Process and outcomes. Kamu-İs, 11(1), 167-183.

Hochschild, A. R. (1983). The managed hearth: Commercialization of human feeling. University of California Press: Berkeley.

Isenbarger, L., \& Zembylas, S. M. (2006). The emotional labor of caring in teaching. Teaching and Teacher Education, 22, 120-134. https://doi.org/10.1016/j.tate.2005.07.002

Kaplan, M. \& Ulutaş, Ö. (2016). The effect of emotional labour on burnout: A case of study in hotel businesses. Selçuk University Journal of Institute of Social Sciences, 35, 165-174.

Kaya, U., \& Serçeoğlu, N. (2013). Work alienation among emotion workers: A research in service industry. Work and Society, 36(1), 311-347.

Khan, M. A. (2012). Impact of emotional labour on emotional exhaustion, and moderating role of social support: An empirical study on hospitality industry in Pakistan. Actual Problems of Economics, 5, 321-329.

Koçak, O., \& Gürsoy, G. M. (2018). The relationship between emotional labor and burnout. HAK-IŞ International Journal of Labour and Society, 7(17), 161-181. https://doi.org/10.31199/hakisderg.372622

Konakay, G. (2013). A research about the relationship between emotional intelligence factors and burnout factors of academicians: Case of Kocaeli University. Dokuz Eylül University Journal of Institute of Social Sciences, 15(1), 121-144.

Köklü, N., Büyüköztürk, Ş., \& Bökeoğlu, Ç.Ö. (2007). Statistics for social sciences. Ankara: Pegem

Köse, S., Oral, L., \& Türesin, H. (2011). The relationship between emotional labour and employees' burnout levels: A research on health sector. Dokuz Eylul University Journal of the Faculty of Business, 12(2), 165-185.

Lazar J. (2001). Communication science. Edt. Anık C. (1th ed.) Vadi Publications. Ankara.

Lee, Y. H., \& Chelladurai, P. (2018). Emotional intelligence, emotional labor, coach burnout, job satisfaction, and turnover intention in sport leadership. European Sport Management Quarterly, 18(4), 393-412. https://doi.org/10.1080/16184742.2017.1406971

Maslach, C. (2003). Job burnout: New directions in research and intervention. Current Directions in Psychological Science, 12(5), 189-192. https://doi.org/10.1111/1467-8721.01258

Maslach, C., \& Goldberg, J. (1998). Prevention of burnout: New perspectives. Applied and Preventive Psychology, 7(1), 63-74.

Maslach, C., \& Jackson, S. E. (1981). The measurement of experienced burnout. Journal of Occupational Behavior, 
2, 99-113.

Maslach, C., Schaufeli, W. B., \& Leiter, M. P. (2001). Job burnout. Annual Review of Psychology, 52(1), $397-422$. https://doi.org/10.1146/annurev.psych.52.1.397

Morgan, G. A., Leech, N. L., Gloeckner, G. W., \& Barrett, K. C. (2004). SPSS for introductory statistics: Use and interpretation. Psychology Press.

Morris, J. A., \& Feldman, D. C. (1997). Managing emotions in the workplace. Journal of Managerial Issues, 9(3), 257-274.

Oral, L., \& Köse, S. (2011). A research on phsicians use of emotional labor and the relationship between their job satisfaction and burnout levels. The Journal of Faculty of Economics and Administrative Sciences, 16(2), 463-492.

Özgen, I. (2010). Emotional labor in tourism enterprises. Ankara: Detay Publishing.

Sağlam, A. Ç. (2011). Relationship of socio-demographic characteristics of academicians with their burnout levels. Mustafa Kemal University Journal of Social Sciences Institute, 8(15), 407-420.

Serin, S. (2014). The effect of emotional labor on burnout and job satisfaction: An application in the health sector. Master's Thesis, Türk Hava Kurumu University Institute of Social Sciences, Ankara.

Theodosius, C. (2008). Emotional labour in health care: The unmanaged heart of nursing (1th ed.). New York: Routledge.

Uğur, H. (2014). The relationship of the some social demographic properties of the coaches who works on turkish football leauges with the burnout levels on 2012-2013. Master's Thesis, Dumlupinar University, Institute of Health Sciences, Kütahya.

Yıldız, E. (2012). Burnout and a research on guidance counselors. Journal of Institute of Social Sciences, 1(33), 37-61.

Yılmaz, K., Altınkurt, Y., Güner, M., \& Şen, B. (2015). The relationship between teachers' emotional labor and burnout level. Eurasian Journal of Educational Research, 59(15), 75-90. http://dx.doi.org/10.14689/ejer.2015.59.5

Youngmi, K. (2016). Emotional labour and burnout among public middle school teachers in South Korea, Master's Thesis, University of Jyvaskyla, Finland.

Zhang, Q., \& Zhu, W. (2008). Exploring emotion in teaching: Emotional labor, burnout and satisfaction in Chinese higher education. Communication Education, 57(1), 105-122. https://doi.org/10.1080/03634520701586310 